\title{
Action Research in a Non-Profit Agency School Setting: Analyzing the Adoption of an Innovation after Initial Training and Coaching
}

\author{
Elena Sandoval-Lucero ${ }^{1}$, Johanna B. Maes ${ }^{2} \&$ Georgia Pappas $^{3}$ \\ ${ }^{1}$ Division of Student Affairs, Community College of Aurora, Aurora, Colorado, USA \\ ${ }^{2}$ Department of Ethnic Studies, University of Colorado Boulder, Boulder, Colorado, USA \\ ${ }^{3}$ Department of Global/Nonprofit Leadership Development, Regis University, Denver, Colorado, USA \\ Correspondence: Elena Sandoval-Lucero, Community College of Aurora, 16000 E CentreTech Parkway, Aurora, \\ CO., 80011, USA. Tel: 1-303-360-4824. E-mail: elena.sandoval-lucero@ccaurora.edu
}

Received: January 13, 2012

Accepted: January 31, 2013

Online Published: February 22, 2013

doi:10.5539/jel.v2n1p262

URL: http://dx.doi.org/10.5539/jel.v2n1p262

\begin{abstract}
Action research is a method of organizational development and improvement often used in educational settings. This study implemented an action research process in an alternative school that serves students with significant special needs. The action research process was implemented by classroom teams who developed a research question, collected and analyzed data, and made decisions about how to improve their current practices based on the data. The action research training project consisted of three stages: training in the protocol of action research, follow-up coaching and on-site assistance to participants, and a follow-up study. There were eleven instructional teams, made up of teachers, paraprofessionals, and therapists that took part in the training. One year after the initial training, one-on-one interviews were conducted with sixteen participants for the follow-up study. Eleven people reported that they were continuing to use action research in their classrooms and five people reported they were not. Teacher leadership to implement the process, viewing action research as part of their daily job duties, valuing the collaborative aspect of the process, and valuing the opportunity to serve students better contributed to continued use of action research. Staff turnover, lack of time, and lack of motivation contributed to discontinued use.
\end{abstract}

Keywords: action research, organizational development, education, nonprofit, human service agency, program process improvement, participatory action research, cooperative inquiry, action learning

\section{Introduction}

Action research is a process in which workgroups examine their own practice using research techniques and carefully designed plans in order to improve organizational outcomes (Bjørn \& Boulus, 2011; Coghlan \& Brannick, 2005; Dick, 2009; Ferrance, 2000). In school and non-profit settings, action research generally involves a group reflective process involving both targeted inquiry and group discussion as part of the overall research process (Amble, 2012; Ferrance, 2000; Stringer, 2007). Action research differs from traditional research in that the study is conducted by people who are a part of the phenomenon being studied (Cain \& Milovic, 2010). In agency settings, action research is also often used as a means of organizational improvement and development, and is a collaboration between the researcher and the agency staff (Cunningham, 2008; Dick, 2009; Snoeren, Niessen, \& Abma, 2012).

This study examined action research in an alternative school setting within a non-profit human services agency. The school, designed to serve students with significant special needs, is housed within a non-profit agency serving people with developmental disabilities from birth to senior citizen. The school program serves students who are referred from public k-12 schools for temporary placement to support and stabilize them before they transition back to their home school. Students must have two diagnoses: an IQ of 72 or below and a second diagnosis as documented in an Individualized Education Plan (IEP) to be placed at the school. Initially, we were asked to provide action research training to the staff of this school with the goals of both professional and organizational development. The project became two-tiered. First, we examined the results of the training itself. Second, we examined the degree to which the staff adopted the innovation of action research following conclusion of the training. 
The action research process acted as a lens through which the education teams could objectively analyze and improve upon their practices using data they gathered. The action research paradigm is used to solve practical problems that arise out of daily practice and are of concern to all team members. (Bennett \& Monsen, 2011; Cain \& Milovic, 2010). Action research is also highly valued in educational settings as a professional development activity because it increases confidence and knowledge, improves data collection and analysis skills, leads to informed reflective practice, and improves outcomes for students (Bennett \& Monsen, 2011; Cain \& Milovic, 2010). However, participating in action research for professional development does not always lead to changes in educational practice (Cain \& Milovic, 2010). Zeichner (2003) recommends a specific set of conditions that are necessary for action research to change practice. They include autonomy to develop action research projects that are challenging and stimulating, sufficient time to conduct action research, a supportive work-group in which to conduct action research, and providing a school day structure that is conducive to developing communities of researchers (Zeichner, 2003).

\subsection{The Training Intervention}

\subsubsection{The Training Agency}

Founded at a time when public schools would not accept children with special needs, and when few other services were available for children with disabilities, the participating agency began as a school to offer support, education and training to children with developmental disabilities. Over the years the services have expanded and the agency is now serving people with disabilities from birth to senior citizens. The alternative school program was the focus of the action research training.

\subsubsection{The Training}

During the fall of 2009, we were asked to deliver an action research training session with staff at the agency's alternative school. The overall goal of the action research training was to help instructional teams (teachers, paraprofessionals, and therapists) work together on action research projects. The instructional teams worked together to reflect on:

1) Where we are going with our students?

2) How will we get there?

3) How can we evaluate our results?

In addition, the administration at the facility hoped that by involving all staff in creating meaningful outcomes and change for their students, it would positively impact staff morale and employee attrition. Because the school serves such a challenging student population, burnout and staff turnover were a concern.

The action research facilitators trained teachers, therapists, and paraprofessionals all together on action research methods during a day-long session. The team training approach is a research-based best practice. For example, Stringfield (2000) found that high achieving Title I schools generally included professional development involving both teachers and paraprofessionals. Storey, Smith, \& Strain (1993) similarly found that positive student outcomes resulted when through systematic training, paraprofessionals and teachers were trained together, and follow-up coaching was used to assure transfer of training to the classroom.

The study's action research approach builds upon the work group discussion model, which grew out of the need for supervision, learning, and training in human service settings (Amble, 2012; Warman \& Jackson, 2007). Work discussion groups provide an opportunity for staff to share client-related concerns, challenges, and issues (Amble, 2012; Bjørn \& Boulus, 2011; Warman \& Jackson, 2007). Action research provides a model in which the work discussion group can make data-informed decisions about resolution of issues. Like action research, work discussion groups encourage reflective practice (Amble, 2012; Bjørn \& Boulus, 2011; Warman \& Jackson, 2007). This training model focuses on work relationships and professional learning. Supportive relationships at work affect job satisfaction and reduce stress that can lead to attrition (Taylor, 2008). The effectiveness of group collaboration is related to the interdependent relationships, and innovative learning (Meirink, Imants, Meijer, \& Verloop, 2010). In this instance, the interdependent relationships stem from the fact that the instructional teams already work together in their classrooms. The innovative learning comes from the introduction of action research as a tool to examine their practice, and improve outcomes for their students.

The initial training goals were to help instructional teams understand what action research is, and how to implement it in their classrooms. We approached this using a variety of information and interactive activities designed to give a broad overview of the action research process. By the end of the initial training, the teams worked to identify a research question, and started developing a plan for collecting data to help them discover the answer. 


\subsection{The Coaching}

After the completion of the training, we provided follow-up coaching to participants. Coaching following training has been a best practice standard in educational skill development since the 1980s leading to long term retention of new teaching models and strategies (Fullan, 1990; Joyce \& Showers, 2002, 1996, 1995, 1988; Loucks-Horsley, Stiles, Mundry, \& Love, 2009; Roach, Kratochwill, \& Frank, 2009). Coaching also helps those adopting an innovation to move to higher levels of use (Roach, et al., 2009). We returned to the facility several times a month for the remainder of the school year. On coaching visits, we met with individual teams to help them work through the steps of the action research process.

Coaching was included to facilitate transfer of training to the classroom. Coaching instructional staff has been effective in increasing teacher efficacy, as well as, the use of new innovations and instructional strategies (Duchaine, Jolivette, \& Frederick, 2011; Roach, et al., 2009; Rudd, Lambert, Satterwhite, \& Smith, 2009; Shidler, 2009). Coaching is an effective way of embedding professional development in the instructional setting in order to facilitate better retention of knowledge and skills learned in training (Roach, et al., 2009; Stover, Kissel, Haag, \& Shoniker, 2011; Taie, 2011). When teachers and coaches work together, effective transfer to training to the classroom is more successful (Knight, 2011; Roach, et al., 2009; Stover et al., 2011). Because the coaching for this project took place with instructional teams, there was also a peer-coaching component. Throughout the coaching sessions coaches and team members alternated roles in order to provide support for learning, and achievement of shared goals (McDermott, 2012).

\subsection{The Action Research Projects}

In the spring of 2010, following the training, we returned for a full day to observe the teams presenting their action research projects to their colleagues. The goal was for the classrooms to incorporate the action research process as a regular part of their team interaction and planning. We theorized that once the teams had experienced the process, were provided with coaching support to implement action research, and saw its usefulness, they would be able to conduct multiple action research projects in their classrooms in future years. We took detailed field notes on the content of their projects, in addition to the process they used to complete them. The following is a summary of selected projects. While brief, they do provide an overview of process and key findings. They are representative of both the variety of projects, and the participant's voices and perspectives.

\subsubsection{Collaborative Teaching Model}

Two classroom teams implemented this project. The school was discussing moving to a collaborative teaching model. They wanted to pilot the model, provide feedback, and advise the school on moving to collaborative teaching.

Question: Will problematic behaviors decrease and academic achievement increase with the implementation of the collaborative teaching model in our classrooms?

Baseline data: The team collected behavioral data, and reviewed their student's IEP goals prior to implementing the collaborative teaching model.

Plan and implementation: The team identified lessons and activities that needed a) more staff to manage them; $b$ ) more time to complete; and c) more students to increase efficacy. They developed collaborative lesson plans for art, music, cooking, math, and club activities. They videotaped the collaborative activities for the team to review afterward. They distributed the lesson plans to the paraprofessionals each day, and trained everyone on the application of data collection sheets to indicate the number of prompts required for each student to complete the activity.

Results: In their art lesson they had 100\% productivity from all students. There were no behavioral incidents. All students completed their work with less verbal prompting. They had similar results for the cooking lesson. For the music lesson, not all students sang. However, they all paid attention and there were no behavioral incidents. For the math lesson they were able to group students by skill level and provide scaffolding assistance. All students participated in the group lessons. There were no behavioral incidents. For the club basketball game, three students did not participate, but this was the norm. Only one student had to be removed for behavioral reasons. In reviewing the videos of the collaborative lessons, the staff noted that students seemed calmer and engaged, although a few did not fully participate. Overall, some students needed no prompting to complete the task or activity, and some students needed fewer after they understood the expectations.

Conclusions: The staff and students responded positively to the collaborative teaching model. The collaboration created an increase in the teacher student ratio to $11: 17$, and reduced the number of behavioral incidents. There 
were fewer prompts needed and less 1:1 staffing since some staff could conduct the lesson, and others could observe and prompt when necessary. It was easier to redirect students with more staff. They observed that it was good for the students socially to interact with more people. The students got along better with one another. Those students who provoked others could be put in a different group to reduce arguments. Grouping students by ability and not age or disability, reduced arguments created by different levels of functioning, increased student focus, decreased lesson wait time while students of varying abilities caught up, and reduced behavioral incidents overall. The staff observed that the collaborative approach became easier as the students got to know the staff from the other room. Finally, they noted another benefit was having a consistent behavior system that would help the students adapt more quickly if they were ever moved to another classroom.

\subsubsection{Music in the Classroom}

This project was completed by a team working with one student with significant support needs. They wanted to determine if music would help improve his daily behavior, and if yes, then what type of music. They operationally defined behavior as only that which would stop work in the classroom. The specific behaviors they were interested in reducing were throwing objects at staff, grabbing staff, and rocking. The teacher had previously studied the effects of music on behavior.

Question: What type of music will most effectively change a student's behavior?

Baseline data: To collect baseline data, the team spent one week with no music in the classroom and tracked the incidences of throwing, grabbing, and rocking behaviors.

Plan and implementation: After the baseline week, the team spent one week playing only music with 60 beats per minute or less. They had examined research in the planning phase that indicated that music of $60-70$ beats per minute had a calming effect and resulted in less behavior in some students. The second week they played music with only 90 beats per minute. The next week they tried music with even higher beats per minute. They tracked the students' behavior at regular intervals collecting 1300 separate data points.

Results: The raw data was varied, but showed a steady decline in behavior. With silence or 60 beats per minute there was a much higher incidence of behaviors. At 90 beats per minute the students' behaviors decreased significantly and he enjoyed most music that was even faster.

Conclusions: The team concluded that making music consistent each week reduced the students' behavior overall. They changed classroom practice to make the students' favorite music a reward for good behavior.

\subsubsection{Random Acts of Kindness}

This team's project involved volunteering each week to help out another classroom by bringing them breakfast or lunch, offering to clean up their classroom after an activity, clean the kitchen when it was their turn, or by putting small gifts or inspirational notes recognizing accomplishments in their mailboxes.

Question: Will random acts of kindness improve employee morale in the school?

Baseline data: To collect baseline data the team handed out preliminary surveys asking them what kind of special recognition they would most appreciate. Using these surveys, they designed an implementation plan to help one classroom each week.

Plan and implementation: After each weekly project, they did a follow-up interview with the staff in the classroom they selected. They also kept reflection journals on their observations of teamwork and staff morale in the school.

Results: The preliminary data revealed that $80 \%$ of the staff rated team/school morale as fair, $20 \%$ rated it great, and $0 \%$ gave it the highest ranking of excellent. Following the "random acts of kindness" $75 \%$ rated morale as great and $5 \%$ as excellent. Their reflection journals revealed some additional information. Upon request, the research team planned a group event after work, but noted that some of the attendees appeared to be totally disengaged at the event. They also noted that there were roadblocks to getting kindness projects completed. Classes were confused by what they were trying to do. They thought this was because they initially tried to do this anonymously, but determined it worked better if they were upfront about selecting a classroom for assistance. The project was also time-intensive. They had only completed random acts of kindness with five of the ten other classrooms by the presentation day.

Conclusions: They planned to continue these random acts of kindness as they felt most of the staff responded positively to them. In fact, other classrooms had offered to help once they knew what they were doing. They also suggested finding other ways to promote collaboration and teamwork that was less time consuming. 


\subsubsection{Improving the Transition Process}

This project was completed by a team working with students who were either transitioning to other classrooms, back to their school districts, or into adult placements. They noticed that students and families struggled with transition, and wanted to examine and streamline their processes.

Question: What are the needs and concerns, of staff, students, and families during transition?

Baseline data: To collect baseline data the team spent time reviewing how and why students are transferred within and outside the agency.

Plan and implementation: The team surveyed school staff, students' families, adult program staff, and school district personnel to get their input on the transition process. After analyzing the data they went back to those surveyed to clarify information and answer additional questions that emerged from the data analysis. The team implemented changes to the current transition processes, and collected data on student behavior and adjustment. New processes were developed with a focus on advocacy and accountability.

Results: The first transition process that was evaluated was the one that transitions students from one class to another. This process was the easiest to examine, since the entire process was managed within the school. The new process involved the following steps: First, hold a team meeting to discuss benefits of transitioning of the student(s). Next the classroom team would meet with the IEP team to discuss educational needs. Once transitioned, a staff person from old classroom observes in the new classroom periodically. The new process resulted in less problematic student behavior in transitions.

The team only had time to recommend a change to the adult transition process during the action research project period. They developed recommendations in collaboration with the adult transition team. The adult program begins the transition data collection a year before the transition to an adult placement. Six months prior staff members and the client visit possible agencies. The client has several overnight trial visits. Time constraints did not allow them to test the effectiveness of this new process, but they planned to continue to work to improve adult placement transition.

Finally, the team only began talking about how to make improvements to the public school transition process. They noted that most students are referred to the agency from districts for a temporary placement due to unsafe behavior. However, districts are often reluctant to take students back. The team wanted to work on having a consistent definition of unsafe behavior across districts and recommended that Response to Intervention (RtI) be implemented in order to have students placed at the agency. They did not have time to have this approved and implemented, but were committed to continuing to work toward that goal.

Conclusions: The team concluded that they had taken on too large of a project for the action research project timeline, but noted some positive outcomes of their project. First the project generated some meaningful discussions among all the partners working toward successful transition. Second, it was helpful to include teaching assistants, who provide daily support to students, in the transition process. Third, the agency needs a dedicated transition team as this work was time consuming and they did not make as much progress as they had hoped due to their extensive duties in the classroom.

\section{The Follow-Up Study}

\subsection{The Purpose}

To continue to investigate the impact of action research training and implementation on instructional teams at the agency, we conducted a follow-up study to be completed during the next school year in the fall of 2010 . The goal of the follow-up study was to determine how many of the teams were continuing to use the action research process to improve outcomes for their students and build team morale.

Staff development interventions that include training and coaching are most successful when they have a clear and focused theory of change that underlies their implementation (Walker \& Matarese, 2011). The Concerns Based Adoption Model (CBAM) (Loucks, Newlove, \& Hall, 1975) is the theoretical framework for this follow-up study. The CBAM model is specific to the context in which people change, and proposes that people are influenced during the change process by those they respect (Loucks, et al., 1975). Consistent with Bandura's theory of development (Bandura, 2002), the CBAM model indicates that people engage with and adopt an innovation if others around them, who they perceive to be like themselves, also adopt an innovation (Loucks, et al., 1975). The steps in the CBAM model, which include awareness, information, personal concerns, management, consequences, collaboration and refocusing, are also highly correlated with the action research process (Khoboli \& O'Toole, 2012). This made the CBAM framework a good fit this study. Using the concerns 
based adoption model allowed us to assess the effectiveness of promoting change in educational settings (Roach, et al., 2009). However, we were also aware of the impact of structures and systems in the research context can have on participant outcomes (Snoeren, et al. 2011), thus we focused on the individuals experience with action research, and their interaction with others in the context of using action research during the interviews.

\subsection{The Methodology}

To avoid having participants in the follow-up study feel pressured to exaggerate the level of action research currently being used in their classrooms; we hired an external interviewer to conduct individual interviews with at least two members of each team who completed the action research training. This would avoid the researchers, who were also the trainers, having to conduct the interviews. The interview protocol was developed using the Levels of Use protocol, an instrument that produces results that are highly correlated to behavioral observations (Hall, Loucks, Rutherford, \& Newlove, 1975). The LoU protocol is a semi-structured interview instrument that gives the interviewer several decision points at which to decide if the interviewee is a user or a non-user based on behaviors that are characteristic of each level of use of an innovation, and then moves through an additional series of questions accordingly (Hall, et al., 1975). Interviews are much less time consuming and a more efficient way of establishing levels of use (Loucks, Newlove, \& Hall, 1975). We believed the interviewer had to be a neutral person not affiliated with the agency administration who arranged the training or the trainers who delivered the training. This was the most effective method of getting honest and accurate answers as to the adoption of action research as a regular practice. The interview protocol for this study is included in appendix A at the end of this article.

The sampling method for each phase of the study was purposive. The intent of purposive sampling is to find participants in settings where the phenomenon under study is most likely to occur (Denzin \& Lincoln, 2000). We needed to interview people who had participated in the entire action research training and coaching process the previous year. Consequently, we invited participation from teachers, paraprofessionals and therapists who had been members of instructional teams from the eleven classrooms that had participated in the action research training the previous academic year. Participation was voluntary, and participants were ensured their identities would remain confidential. Once interest in participating in the interview was expressed by school staff members, the interviewer scheduled a day and time to meet. Interviews were semi-structured guided by the LoU interview protocol developed for the study. Each one lasted approximately an hour

Data was transcribed and analyzed using the "Levels of Use" LoU rubric, which takes into consideration that adoption of an innovation is a developmental process that is completed by members of an organizational at different rates and levels (Hall, et al., 1975; Loucks, et al., 1975). The key in analyzing the data is to identify events and conditions that impact the instructional staff members' use of action research based practices in the classroom (Roach, et al., 2009). Individual interviews were analyzed to determine levels of use of action research within classroom teams at the agency. The process of analyzing LoU data began with the research team developing of an 'Innovation Configuration' that specifies the conditions associated with use and non-use of each practice or component. The innovation configuration used for this study is included in appendix B at the end of the article. The tape-recorded and transcribed data were then compared to a well-developed rubric using the CBAM "Levels of Use" concepts as the a priori hypotheses. Each interviewee was thus scored as either a "user" or a "non-user" of the identified innovation. Users were further classified by the amount and integrity of their use. For this study, levels of use helped define the context in which these instructional teams worked.

\section{Results}

Sixteen people were interviewed for the follow-up study, of which, eleven reported that they were continuing to use action research in their classroom teams, and five reported that they were not. The users would be classified as novice users among the CBAM model's seven levels (Hord, Rutherford, Huling-Austin, \& Hall, 1987; Roach, et al., 2009). Six would be classified as mechanical use of the innovation where changes and adjustments are still being made to better organize and master the tasks of use (Hord, et al., 1987; Roach, et al., 2009). Five would be classified as routine meaning the user has established a pattern of use that is comfortable and routine (Hord, et al., 1987; Roach, et al., 2009). The non-users would be classified as mostly on the lowest level of non-use characterized by showing no interest and taking no action to use the innovation (Horn, et al., 1987). Although one non-user could be classified as being at the orientation because the person was taking initiative to learn more about the innovation, but was still a non-user (Hord, et al., 1987). An analysis of the interview transcripts yielded key themes for both groups. 


\subsection{Action Research Users}

\subsubsection{Teacher Leadership Matters}

Those staff members who considered themselves users of action research had teachers who believed in the value of the process, and provided leadership to the team to implement it in their classroom. Teacher leaders who could clearly articulate the benefits to students were able to successfully sustain its use in their classrooms. As one teacher stated:

I think it's really beneficial for me as a teacher working with students with behaviors just to pinpoint [behavioral or classroom changes needed] and to follow through. We could take some sort of data to see what the results are, and make decisions about whether or not we need to continue doing it, change it, stop doing it. I think it's just a nice way to be more intentional about what we do on an everyday basis as teachers trying to help our students in the classroom.

Another described it this way:

I see action research as an opportunity to address your current state of processes, some of the challenges and the barriers to the goal, and set up specific tasks in order to accomplish those goals, whether it be a micro goal or a larger macro goal.

Teachers who provided leadership for continued use of action research, also found value in the team building aspect of action research. One teacher described initiating the project, "I think that it starts as a really great brainstorm, again the strength is that you get some team unity and buy in to address the challenges and the goals." Teachers also identified team strengths, and built on them in order to create interest and buy in for the action research project. One teacher specifically mentioned his team member's strengths and contributions to the project, "One of the [paraprofessionals] in my class is very musical, and he knows all about [music and behavior]. He did a lot of research for us, which was good background." The team then made decisions as a group about how to proceed with their research.

\subsubsection{Incorporating Action Research into Daily Routines}

The teams that continued to use action research after the initial project also viewed action research as part of their daily job duties. One paraprofessional described her current participation with the action research process:

I'm a very active participant in action research. I do data collection every day. I help with the assessments and calculations, quantifying data entry, everybody does. I'm an active participant in discussions that we hold in our classroom and clusters on how we're adapting and modifying each project to better suit what's changing.

Teams who continued to use action research felt like it was something they already did, and valued its continued use. One paraprofessional stated, "I feel like we do [action research] already in the classroom. It's a very good system for classrooms that are struggling with [student issues]. Another team member said, "I think it's ingrained in our system." A paraprofessional clearly understood that the data collection piece was part of her job duties:

I am because part of my job is to record data tracking for the students and one of the ways we do that is with the ABC model which is the antecedent - behavior - consequence model. I often observe students in the classroom. When they're engaging in behaviors, I'm tracking the data about what's going on, and we're using that data to apply it to change or fix this behavior. I feel that that is doing [action] research.

Active participants in action research also had realistic expectations for the amount of time it would take, and made the time to do it. One paraprofessional clearly stated his time expectations:

We continued to collect data, which is easy to do because it happens right there, but it's the formulating it into actual worthy results that people can see [that takes time]. I don't think people need tons of time to do it, but I would say at least a good hour or two a week depending on the project.

\subsubsection{Valuing their Role on the Team}

Active users of action research valued the collaborative aspects. They believed that team members each had a role in the action research process. They understood the value of having everyone participate. One paraprofessional stated:

Basically it's positive that by working together it feels like a collaborative effort. I think if you have a collaborative effort that makes your achievement more worthwhile because you feel 
like you all did it together, instead of just one person doing it.

Others could clearly articulate team approach to conducting action research. The steps in the action research process were understood, and each person believed he or she had a role to play in the process. A paraprofessional described her team's approach:

We work together to identify the problem, then brainstorm ideas of how to solve that problem, there's research involved, and then once we identify possible solutions, we see if it works.

\subsubsection{Student Centered Focus}

Finally, active users of action research valued serving students. One paraprofessional talked about the efforts to serve students better:

We accumulate data, we continually process that data and see which way it's taking us then go in different directions based on the data we get. I think we're constantly striving to make changes, and do better things for the kids. I think we're always using action research.

A therapist assigned to one of the teams said, "I think it's important to show what the kids are actually doing with solid data because you can't argue with solid data really."

\subsection{Action Research Non-Users}

A review of the interview transcripts also yielded consistent themes in the coded data for those classified as non-users. Many non-users mentioned staff turnover that impacted the progress of their action research project. They also cited lack of time and lack motivation as obstacles to continued use of action research.

\subsubsection{Staff Turnover}

Several of the non-users interviewed mentioned that there were staff changes, particularly teachers who left during the project that impeded their progress, and prevented them from developing a cohesive team that could sustain the action research project. One paraprofessional described staff changes as affecting communication, "We had a change in teachers and a lot of the communication got lost along the way." This impact was mentioned by others, "Not a lot, like I said our project disappeared with the faculty member." Those who lost their teacher during the initial action research project also lost their project leadership. Another paraprofessional stated, "We started with our teacher. She did a lot of the organizing. I did help out. There was a change in staffing." Teachers who came after the initial training were not informed of the action research projects by the school administrators, and therefore could not continue them. One paraprofessional relayed his experience, "Our project fell by the way side. Other things came up, we had a new teacher and everything went one way and anything that wasn't discussed [was dropped]." One paraprofessional admitted that no one told the new teacher about the action research project:

There was a change in staffing. Initially I would say the problems we found we were prepared [to address] until later on when our teacher left. We saw how easily that can get lost when a new teacher coming in is just trying to learn [how we do things]. It was a side project. I don't think it got relayed to her and it faded out of the forefront.

Paraprofessionals who transferred to different classrooms or different positions within the agency also lost touch with their teams' action research projects. One told us she did not know what ever happened with the action research project, "I'm not entirely sure. I left the room - I transferred to a different room, and became uninvolved."

\subsubsection{Lack of Time to Conduct Action Research}

Lack of time was a huge factor that impacted the classroom teams' ability to continue doing action research. It was mentioned repeatedly by the non-users. One teacher talked about her struggles with keeping her team focused on the project due to time constraints, "If we had more time. I think time constraints here play a role in a lot of things." Those non-users who actually worked with a team to complete an action research project mentioned time constraints frequently. One paraprofessional stated, "The only thing I can say is maybe its a little time consuming." Another agreed, "It just took a lot of time outside of school."

Unlike the users, non-users struggled with finding ways to incorporate action research into their daily routine. One teacher admitted the challenges in her classroom made data collection difficult:

Most of it had to do with time constraints. Things have been pretty chaotic in my classroom. I just had to stop because of time constraints, meaning not enough time to devote to collecting and analyzing data, and really taking a look at it. 
Teachers as well as paraprofessionals noted the time constraints they felt prevented them from participating in action research. A paraprofessional described being consumed by other duties:

As far as meetings outside of [class], I [think] teacher meetings are much more cohesive and the amount that the [paraprofessionals] can share between classes is usually bogged down by paper work. There isn't a whole lot of time to talk outside of your classroom time.

Non-users did not describe clear systems for collecting data, and finding time to analyze it as a group. A paraprofessional related her team's struggles with taking time to collect the initial data, "Probably the only weaknesses would be that we're not collecting data. I mean we have a really great team but we're not always perfect at it because we're very busy." Another paraprofessional who participated with data collection described the lack of planning to discuss the results as a team:

Here it's not integrated into a time line. It's started, you do it but then nobody really talks about the successes or the failures of it. It's sort of a project that kind of just gets shelved and nobody ever mentions it again.

The belief that teams were too busy to take the time needed was common among the non-users for both the initial project, and continued use of action research one paraprofessional stated:

I know a lot of people were talking about the action research project, and saying it was difficult for them to actually have time. They would [identify] projects, but it was difficult for them to figure out their projects while they were working with their students because they were so busy with their work. They had a difficult time applying it while working. They didn't feel like they could really get a good project going.

\subsubsection{Lack of Motivation to Conduct Action Research}

Concurrent with the discussion of the time constraints that prevented action projects from being initiated, competed, or continued, were comments that revealed a distinct lack of motivation to do action research. Although action research is designed to build community, some staff was not empowered to participate. One paraprofessional's lack of knowledge about her team's action research project was striking, "It's hard to say, I don't know where it came from. I mean I'm just the [para], I'm not the boss." Another paraprofessional stated. "We had no time or energy to do anything about it - us [paraprofessionals]." Yet another felt it was only useful for teachers:

Action research is more used by the teacher when it comes to planning for the year. I have my input as far as what I can provide the student, but it's more what the teacher puts in place for goals and things like that.

The lack of empowerment to participate in action research was expressed by some non-users as a lack of team unity. Action research was not viewed as a tool to promote the development of teams. One paraprofessional stated,

I think the issue is [about] whoever the team leader is, the supervisor or the teacher, allows [action research] to happen where I think that it takes a wrangling of team unity, and I think team unity is a special ingredient that a lot of people don't foster.

Other non-users were initially resistant to the idea of doing action research at all. One team member stated, "When we started the action research I know that a lot of us [thought] my goodness are you serious? We have to do what?" Rather than looking at action research as a way to improve their practice, non-users looked at it as an indication that they were not working effectively. One paraprofessional felt more like it was an imposition instead of a tool to help them better serve their students:

Thinking of it terms of outside what we normally do, just kind of stressed everybody out. We didn't really understand why we needed to do something outside of what we normally do. We're a good team.

Those teams who looked at their jobs in terms of only what was required were more resistant to the idea of action research. A paraprofessional related her feelings:

On a day-to-day basis... there are so many things that [paraprofessionals] and teachers are responsible for that adding one more thing to track [was too much] especially when it's not a legal requirement.

Some team members participated in an action research project, but felt like not everyone contributed to the same 
degree. While some staff members took the lead, not all were involved equally. As one team member stated:

We had one lead [paraprofessional] who thought of the idea, came up with the questionnaire and did all of that while the rest of us had to watch the kids, and do incidence reports. It seemed like one person was doing most of the work whereas the rest of us were involved peripherally, but not really.

Yet another paraprofessional expressed concerns about how different levels of participation could impact the project outcomes, "I don't know what the word is - biased maybe, or someone doesn't want to track it as much as another person does [so there is] inconsistency in data tracking."

Unlike users who found the intrinsic motivation to incorporate action research into their practice, non-users did not. One paraprofessional stated this lack of motivation very clearly,

We needed more feedback from the team leader. I think there's a lack of intrinsic motivation, and extrinsic motivation isn't there. There's nobody really saying, this is it, if we don't do this, this is what's going to happen.

Another paraprofessional recommended paid overtime as an incentive, "If somehow the time exists, if it's paid over-time, then people [would want] to do action research"

\section{Discussion}

Our results align both with Zeichner's (2003) research on conditions that are conducive to changing practice through action research, and the adoption of research-based instructional practices within the framework of the concerns based adoption model (Roach, et al., 2009). The follow-up study results support those findings, for both users and non-users. First the teams needed the autonomy to develop action research projects that were challenging and relevant (Zeichner, 2003). The team members who continued to use action research felt they worked in an environment that valued their contributions to the classroom team, and thus provided them the autonomy to propose and engage in action research projects that were of interest and value to the team. This was modeled by the teachers who valued each team members' input and contributions to ongoing research. Teachers who plan with team members, and include them in meaningful classroom roles, increase their efficacy and job satisfaction, which are important for continual professional development (Sandoval-Lucero, 2006; 2009). In addition, planning and providing resources for the implementation of new practices is one of the key functions for facilitating school-based change (Roach, et al., 2009).

On the other hand, non-users more often felt powerless to initiate action research, reported a lack of support from the teacher and school directors, or lacked sufficient information about their role in the work. It is not uncommon for change facilitators to encounter practitioners who are resistant to implementing research-based practices to the appropriate level required for integrity of use (Roach, et al., 2009). In this case, the perceived lack of support from school directors may have led non-users to become fearful of defying authority, and less likely to adopt a new change in practice, even when they viewed other teams successfully implementing action research in their classrooms (Cain \& Milovic, 2010). The CBAM model includes several stages of concern involved with adopting innovation that include impact on the organization, management of the task, collecting information, and self-interest (Roach, et al., 2009). In this case, the non-users were focused on the self- interest stage of concern, particularly issues with authority. Therefore, they could neither see the potential beneficial impacts of the action research to their students, nor understand how to manage the action research process.

Zeichner (2003) also citied sufficient time to conduct action research and providing a school day structure that is conducive to developing action research workgroups and communities of researchers as important conditions for producing meaningful change through action research. Our data supported these conditions for both users and non-users of action research. Users clearly stated realistic time expectations for conducting their action research projects. Through teacher leadership, action research practice had also become a normal part of their daily classroom structure. For these instructional teams, continued use of action research to examine and improve their practice became the norm, due to schedules that allowed for action research practice to be incorporated into their routine. One of the biggest complaints from non-users was that action research was too time consuming. In their classrooms, the teacher leaders had not provided a structure that made it possible to fit action research practice into the school day. This made doing action research seem burdensome or overwhelming for non-users. School structures that lack of time to conduct action research have been cited previously as an impediment to continuous use of action research (Kitchen \& Stevens, 2008; Volk, 2010). However, the users in this study were able to overcome this obstacle by creating a daily structure that incorporated action research into practice, and involving all team members so that data collection and analysis became manageable tasks. 
Finally, a supportive work-group in which to conduct action research is an important a condition to effectively produce institutional change (Kitchen \& Stevens, 2008; Ziechner, 2003). Again, our users modeled this practice. The teachers in the classrooms that continued to use action research after the initial project valued each team member's unique contributions to the team. This fostered a supportive work environment in which action research could flourish. Once again, non-users described completely opposite work environments in which one person completed action research in isolation, or in which they did not feel that their role in continually conducting action research was supported. Further, school staff members who are engaging in action research on a continual basis are motivated by a strong desire to improve outcomes for their students, and this desire is communicated throughout the school (Cain \& Milovic, 2010).

Another indication of supportive work group environments came from team members descriptions of their understanding of action research. A narrow definition and understanding of action research can limit its effectiveness as a professional development tool (Volk, 2010). Non-users clearly demonstrated this lack of understanding and narrow definition of action research, whereas users could articulate the action research process and their role in it. Non-users also noted that action research was not a legal requirement. This perspective has been seen in previous research, were school staff use excuses for not doing anything outside their prescribed role (Volk, 2010).

\section{Conclusion}

The moderate success of this action research training points to the need for creating work environments that are more supportive of change. In order to produce school wide change, issues of culture, context, and communication need to be considered (Eldridge, Price, Kushibab, Callahan, \& Yowell, 2012; Roach, et al., 2009). Cultures that support change have a clear mission and vision that is consistent among senior leadership (Eldridge, et al., 2012; Roach, et al., 2009). People in the organization also perceive change positively, are tolerant of change, are open to innovating, and to having the discussion (Eldridge, et al., 2012). While the mission and vision were clearly articulated at the executive level of this organization, and supported by many of the staff members in the school, the school leadership was neither supportive of, nor tolerant of change. This perceived lack of support by school leaders caused the non-users specifically, to feel distrust of the action research process, and to discontinue use after completing the initial project, if they even completed it at all. These staff members were not willing to risk doing anything outside of their prescribed duties due to the inconsistent levels of support for the project.

Context for change requires that employees view past changes as successful, and therefore worthwhile (Eldridge, et al., 2012). It is more about developing a culture of inquiry where data is not collected in isolation without context, and then regularly reviewed in order to explore trends and implications (Chaplot, Johnstone, \& Booth, 2012). Clearly, for the users of action research, this culture of inquiry had been built within certain individual classrooms. These instructional teams understood its importance. Data was considered as important for decision making, and for building capacity to better serve their students (Chaplot, et al., 2012). However, the non-users clearly had additional needs for planning, communication, support, and follow-up in order to influence their adoption of an innovative change in practice (Roach, et al., 2009).

Communication for change requires consistency, inclusivity, open discussion, and regular updates (Eldridge, et al., 2012). The communication within the broader organization was effective for those employees who considered themselves continuing users. Because of executive and teacher leadership, people felt as if their role in the classroom action research was understood and valued. Communication from school leaders was ineffective or non-existent in classrooms that experienced staff turnover. New teachers were not informed of the action research projects, and therefore could not take a leadership role. This made non-users feel marginalized and disengaged from the action research process (Eldridge, et al., 2012). Teacher leadership is the key to effective instructional teams (Chopra, Sandoval-Lucero, \& French, 2011). Further, effective supervision has been shown to promote employee engagement in work discussion groups like those used in action research (Wardman \& Jackson, 2007). Future school-based interventions could emphasize more communication and relationship building on the part of the training consultants in order to provide these essential change management functions for school staff members who did not receive this support within their building (Roach, et al., 2009).

\section{References}

Amble, N. (2012). Reflection in action with care workers in emotion work. Action Research, 10(3), 260-275. http://dx.doi.org/10.1177/1476750312443572

Bandura, A. (2002). Social cognitive theory in a cultural context. Applied Psychology: An International Review, 51(2), 269-291. http://dx.doi.org/10.1111/1464-0597.00092 
Bennett, S., \& Monsen, J. J. (2011). A critical appraisal of four approaches which support teachers' problem-solving within educational settings. Educational Psychology in Practice, 27(1), 19-35. http://dx.doi.org/10.1080/02667363.2011.549351

Bjørn, P., \& Boulus, N. (2011). Dissenting in reflective conversations: Critical components of doing action research. Action Research, 9(3), 282-302. http://dx.doi.org/10.1177/1476750310396949

Cain, T., \& Milovic, S. (2010). Action research as a tool of professional development of advisers and teachers in Croatia. European Journal of Teacher Education, 33(1), 19-30. http://dx.doi.org/10.1080/02619760903457768

Chaplot, P., Johnstone, R., \& Booth, K. (2012). Building a culture of inquiry and using data effectively. NASPA Leadership Exchange, 10(3), 10-13.

Chopra, R. V., Sandoval-Lucero, E., \& French, N. K. (2011). Effective supervision of paraeducators: Multiple benefits and outcomes. National Teacher Education Journal, 4(2), 15-26.

Coghlan, D., \& Brannick, T. (2005). Doing Action Research in Your Own Organization. Sage Publications, Inc.: Los Angeles.

Cunningham, W. S. (2008). Voices from the field: Practitioner reactions to collaborative research initiatives. Action Research, 6(4), 373-390. http://dx.doi.org/10.1177/1476750308097025

Denzin, N. K., \& Lincoln, Y. S. (2000). Part III strategies of inquiry. In N. K. Denzin \& Y. S. Lincoln (Eds.). Handbook of qualitative research (2nd ed, pp. 367-378). Thousand Oaks, CA: Sage.

Dick, B. (2009). Action research literature 2006-2008 Themes and trends. Action Research, 7(4), 423-441. http://dx.doi.org/10.1177/1476750309350701

Duchaine, E. L., Jolivette, K., \& Frederick, L. D. (2011). The effect of teacher coaching with performance feedback on behavior-specific praise in inclusion classrooms. Education and Treatment of Children, 34(2), 209-227. http://dx.doi.org/10.1353/etc.2011.0009

Eldridge, J., Price, J., Kushibab, D., Callahan, C., \& Yowell, S. (2012). Creating environments conducive to change. NASPA Leadership Exchange, 10(2), 22-25.

Ferrance, E. (2000). Action research. LAB, Northeast and Island Regional Education Laboratory at Brown University.

Fullan, M. (1990). Staff development, innovation and institutional development. In B. Joyce (Ed.), Changing school culture through staff development (pp. 3-25). Alexandria, VA: Association for Supervision and Curriculum Development.

Hall, G. E., Loucks, S. F., Rutherford, W. L., \& Newlove, B. W. (1975). Levels of use of the innovation: A framework for analyzing innovation adoption. Journal of teacher education, 26(1), 52-56. http://dx.doi.org/10.1177/002248717502600114

Hord, S. M., Rutherford, W. L., Huling-Austin, L., \& Hall, G. E. (1987). Taking Charge of Change. Alexandria, VA: Association for Supervision and Curriculum and Development.

Joyce, B. R., \& Showers, B. (2002). Student Achievement Through Staff Development (3rd ed.). Alexandria, VA: Association for Supervision and Curriculum Development.

Joyce, B., \& Showers, B. (1988). Student achievement through staff development. New York: Longman.

Joyce, B., \& Showers, B. (1995). Student Achievement through Staff Development: Fundamentals of School Renewal (2nd ed). White Plains, NY: Longman.

Joyce, B., \& Showers, B. (1996). The evolution of peer coaching. Educational Leadership, 53(6), 12-16.

Khoboli, B., \& O'Toole, J. (2012). The concerns-based adoption model: Teachers' participation in action $\begin{array}{lllll}\text { research. Systemic Practice \& Action Research, 25(2), 137-148. } & \text { \& }\end{array}$ http://dx.doi.org/10.1007/s11213-011-9214-8

Kitchen, J., \& Stevens, D. (2008). Action research in teacher education: Two teacher-educators practice action research as they introduce action research to preservice teachers. Action Research, 6(1), 7-28. http://dx.doi.org/10.1177/1476750307083716

Knight, J. (October, 2011). What good coaches do. Educational Leadership, 60-63.

Loucks, S. F., Newlove, B. H., \& Hall, G. E. (1975). Measuring Levels of Use of an Intervention (Report 3013). 
Austin, TX: The University of Texas-Austin, Research and Development Center for Teacher Education.

Loucks-Horsley, S., Stiles, K. E., Mundry, S. E., Love, N. B., \& Hewson, P. W. (2009). Designing professional development for teachers of science and mathematics (3rd ed.). Thousand Oaks, CA: Corwin Press.

McDermott, L. (May, 2012). Tapping the wisdom of peers. $T+D, 70-72$.

Meirink, J. A., Imants, J., Meijer, P. C., \& Verloop, N. (2010). Teacher learning and collaboration in innovative teams. Cambridge Journal of Education, 40(2), 161-181. http://dx.doi.org/10.1080/0305764X.2010.481256

Roach, A. T., Kractochwill, T. R., \& Frank, J. L. (2009). School-based consultants as change facilitators: adaptation of the concerns-based adoption model (CBAM) to support the implementation of research-based practices. Journal of Educational and Psychological Consultation, 19, 300-320. http://dx.doi.org/10.1080/10474410802463304

Rudd, L. C., Lambert, M. C., Satterwhite, M., \& Smith, C. H. (2009). Professional development + coaching = enhanced teaching: Increasing usage of math mediated language in preschool classrooms. Early Childhood Education Journal, 37(1), 63-69. http://dx.doi.org/10.1007/s10643-009-0320-5

Sandoval-Lucero, E. (2006). Recruiting paraeducators into bilingual teaching roles: The importance of support, supervision, and self-efficacy. Bilingual Research Journal, 30(1), 195-218. http://dx.doi.org/10.1080/15235882.2006.10162872

Sandoval-Lucero, E. (2009). The Role of Self-efficacy in Paraeducators Career Decisions: The Impact of Effective Supervision and Support. Saarbrücken, Germany: VDM Verlag.

Shidler, L. (2009). The impact of time spent coaching for teacher efficacy on student achievement. Early childhood Education Journal, 36, 453-460. http://dx.doi.org/10.1007/s10643-008-0298-4

Snoeren, M. M. W. C., Niessen, T. J. H., \& Abma, T. A. (2012). Engagement enacted: Essentials of initiating an action research project. Action Research, 10(2) 189-204. http://dx.doi.org/10.1177/1476750311426620

Storey, K., Smith, D. J., \& Strain, P. S. (1993). Use of classroom assistants and peer-mediated intervention to increase integration in preschool settings. Exceptionality, 4(1), 1-16. http://dx.doi.org/10.1207/s15327035ex0401_1

Stover, K., Kissel, B., Haag, K., \& Shoniker, R. (2011). Differentiated coaching: Fostering reflection with teachers. The Reading Teacher, 64(7), 498-509. http://dx.doi.org/10.1598/RT.64.7.3

Stringer, E. T. (2007). Action research. Sage Publications, Incorporated.

Stringfield, S. (2000). Toward meeting the American Dream: A future for Title I. In D. Taylor \& E. Kemper (Eds.) Title I schoolwide projects: Evidence from the field (pp. 199-210). New York: AMS.

Taie, E. S. (April, 2011). Coaching as an approach to enhance performance. The Journal for Quality \& Participation, 34(1), 34-38.

Taylor, S. E. (2008). Fostering a supportive environment at work. The Psychologist-Manager Journal, 11, 265-283. http://dx.doi.org/10.1080/10887150802371823

Volk, K. S. (2010). Action research as a sustainable endeavor for teachers: Does initial training lead to further action? Action Research, 8(3), 315-332. http://dx.doi.org/10.1177/1476750309351358

Walker, J. S., \& Matarese, M. (2011). Using a theory of change to drive human resource development for wraparound. Journal of Child and Family Studies, 20(6), 791-803. http://dx.doi.org/10.1007/s10826-011-9532-6

Warman, A., \& Jackson, E. (2007). Recruiting and retaining children and families' social workers: The potential of work discussion groups. Journal of Social Work Practice, 21(1), 35-48. http://dx.doi.org/10.1080/02650530601173599

West, C. (2011). Action research as a professional development activity. Arts Education Policy Review, 112(2), 89-94. http://dx.doi.org/10.1080/10632913.2011.546697

Zeichner, K. M. (2003). Teacher research as a professional development for P-12 educators in the USA. Educational Action Research, 11(2), 301-325. http://dx.doi.org/10.1080/09650790300200211 


\section{Appendix A: Levels of Use Interview Protocol}

1. 0-11/111/VI Are you currently using action research on a regular basis to identify problems, plan, collect and analyze data, and reflect on results for future classroom practices and student outcomes?

If No, Continue.

2.

2. Have you ever used action research to identify problems, plan, collect and analyze data, and reflect on results for future classroom practices and student outcomes?

\section{If YES, turn page.}

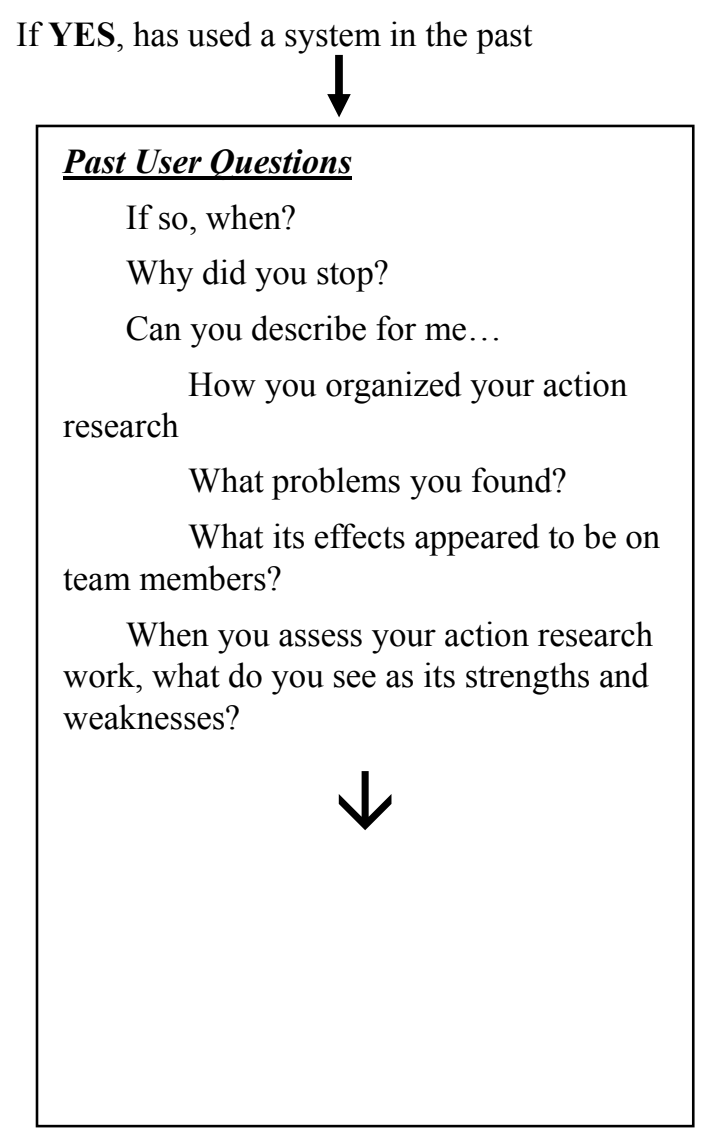

Complete past user interview by continuing with question "0/I-II"
If NO, has not used a consistent system in the past

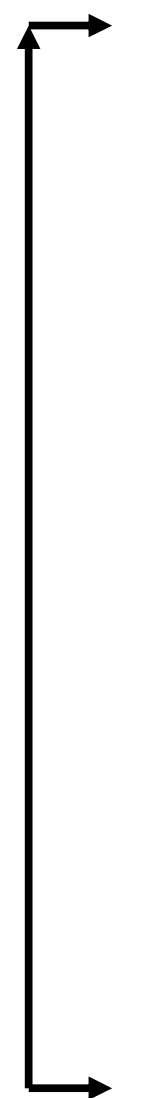

0 / I - II Have you made a decision to use action research in the future?

I / II - If so, when will you begin its use?

Knowledge

Can you describe action research as you see it?

Acquiring Info

Are you currently looking for any information about action research?

Knowledge

What do you see as the strengths and weaknesses of action research?

Assessing

At this point in time, what kinds of questions are you asking about action research?

Sharing

Do you ever talk with others and share information about action research?

Planning

What are you planning with implementing action research? Can you tell me about any preparation or plans you have for using action research?

Status

Can you summarize for me where you see yourself right now Reporting in relation to the use of action research?

(Final Question)

\section{Open Ended Question whether they meet the criteria for being a user:}

3. Can you describe for me some aspects of your action research work, such as (go to the Innovation Configuration to get these probes)

(If at this point, the participant indicates that he/she does not engage in problem identification, planning, data collection, analysis and future planning with the classroom team, to the extent that we would consider him/her a "user," then go back to the "No" side of the interview protocol and start with the 0 / I-II Question - inserting the particular aspects) that they don't do - e.g., Have you made a decision to start collecting data in the future?) 
4. Assessing / Knowledge - What do you see as the strengths and weaknesses of action research in your situation? Have you made any attempt to do anything about the weaknesses?

5. Acquiring Information - Are you currently looking for any information about action research? What kind? For what purposes?

6. LoU V - Do you work with others on action research? Do you meet on a regular basis with your collaborators regarding action research?

\section{If No, Continue directly below}

\section{Sharing}

Do you ever talk with others and share information about action research? What do you tell them?

\section{Assessing}

Have you ever considered alternatives or different systems of action research?

Are you doing any evaluating, either formally or informally, that would affect your action research work?

Have you ever received feedback from team members that would affect the way you use action research?

What have you done with the information you've gotten?

\section{III / IV-A/IV-B}

Have you made any changes recently in how you do action esearch?

What changes? Why? How recently?

Are you considering making any additional changes?

\section{Planning}

As you look ahead to later this year, what plans do you have in relation to using action research?

\section{III - V/VI}

Are you considering or planning to make any major modifications or replace action research with another practice at this time?

\section{Status Reporting}

Can you summarize for me where you see yourself right now in relation to the using action research?

(Final Question)

\section{If Yes, and you suspect Level V, continue below}

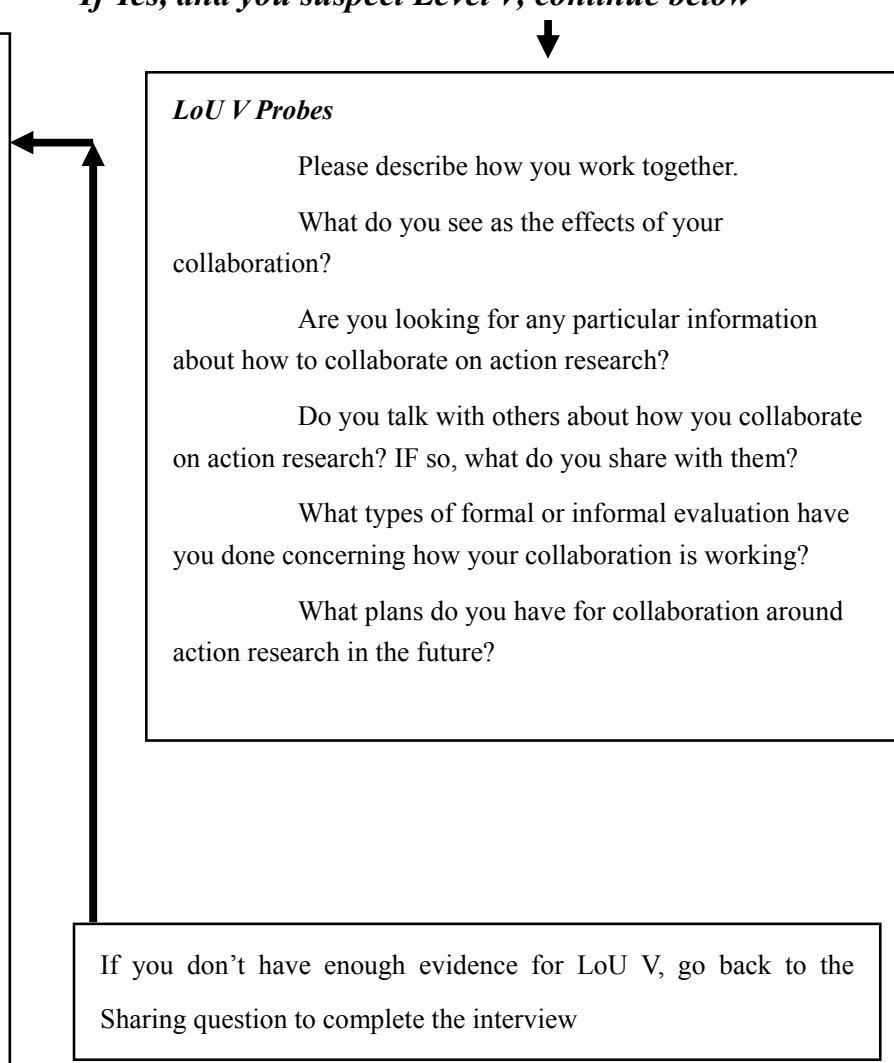

$\boldsymbol{O r}$ - If you have enough evidence to establish LoU V, go to question "III-V/VI to complete the interview. 


\section{Appendix B: Innovation Configuration}

\begin{tabular}{|c|c|c|c|}
\hline Ideal & $\begin{array}{l}\text { Significant Progress } \\
\text { Made/Acceptable }\end{array}$ & $\begin{array}{c}\text { Some Progress } \\
\text { Made/Unacceptable }\end{array}$ & $\begin{array}{c}\text { No progress } \\
\text { made/Unacceptable }\end{array}$ \\
\hline \multicolumn{4}{|c|}{ Phase I Problem Identification } \\
\hline $\begin{array}{l}\text { All instructional teams } \\
\text { are using regular } \\
\text { planning time to } \\
\text { identify classroom } \\
\text { issues/problems and } \\
\text { formulating them as } \\
\text { questions that can be } \\
\text { studied. }\end{array}$ & $\begin{array}{l}\text { Some instructional teams } \\
\text { are using regular } \\
\text { planning time to identify } \\
\text { classroom issues and/or } \\
\text { problems and } \\
\text { formulating them as } \\
\text { questions that can be } \\
\text { studied. }\end{array}$ & $\begin{array}{l}\text { Teachers only are } \\
\text { identifying classroom } \\
\text { issues/problems and } \\
\text { formulating them as } \\
\text { questions that can be } \\
\text { studied. }\end{array}$ & $\begin{array}{l}\text { Instructional teams are } \\
\text { not planning together, } \\
\text { identifying issues to be } \\
\text { addressed or studied. }\end{array}$ \\
\hline \multicolumn{4}{|c|}{ Phase II Plan of Action } \\
\hline $\begin{array}{l}\text { All instructional teams } \\
\text { are developing and } \\
\text { implementing new } \\
\text { strategies to address } \\
\text { their question, or } \\
\text { developing plans of } \\
\text { action to examine } \\
\text { existing practices. }\end{array}$ & $\begin{array}{l}\text { Some instructional teams } \\
\text { are developing and } \\
\text { implementing new } \\
\text { strategies to address } \\
\text { their question, or } \\
\text { developing plans of } \\
\text { action to examine } \\
\text { existing practices. }\end{array}$ & $\begin{array}{l}\text { Teachers only are } \\
\text { developing } \\
\text { implementing and } \\
\text { strategies to address } \\
\text { their questions, or } \\
\text { developing plans of } \\
\text { action to examine } \\
\text { existing practices. }\end{array}$ & $\begin{array}{l}\text { Instructional teams are } \\
\text { not developing and } \\
\text { implementing new } \\
\text { strategies to address } \\
\text { their questions, or } \\
\text { developing plans of } \\
\text { action to examine } \\
\text { existing practices. }\end{array}$ \\
\hline \multicolumn{4}{|c|}{ Phase III Data Collection } \\
\hline $\begin{array}{l}\text { All instructional teams } \\
\text { are regularly collecting } \\
\text { data to examine the } \\
\text { results and outcomes } \\
\text { of newly implemented } \\
\text { or existing practices. }\end{array}$ & $\begin{array}{l}\text { Some instructional teams } \\
\text { are regularly collecting } \\
\text { data to examine the } \\
\text { results and outcomes of } \\
\text { newly implemented or } \\
\text { existing practices. }\end{array}$ & $\begin{array}{l}\text { Teachers only regularly } \\
\text { collecting data to } \\
\text { examine the results and } \\
\text { outcomes of newly } \\
\text { implemented or existing } \\
\text { practices. }\end{array}$ & $\begin{array}{l}\text { Instructional teams are } \\
\text { not regularly collecting } \\
\text { data to examine the } \\
\text { results and outcomes of } \\
\text { newly implemented or } \\
\text { existing practices. }\end{array}$ \\
\hline \multicolumn{4}{|c|}{ Phase IV Analysis of Data } \\
\hline $\begin{array}{l}\text { All instructional teams } \\
\text { are using planning } \\
\text { time to look for } \\
\text { patterns, insights and } \\
\text { new understandings } \\
\text { gleaned from collected } \\
\text { data. }\end{array}$ & $\begin{array}{l}\text { Some teams are using } \\
\text { planning time to look for } \\
\text { patterns, insights and } \\
\text { new understandings } \\
\text { gleaned from collected } \\
\text { data. }\end{array}$ & $\begin{array}{l}\text { Teachers only are using } \\
\text { planning time to look for } \\
\text { patterns, insights and } \\
\text { new understandings } \\
\text { gleaned from collected } \\
\text { data. }\end{array}$ & $\begin{array}{l}\text { Instructional teams are } \\
\text { not using planning time } \\
\text { to look for patterns, } \\
\text { insights and new } \\
\text { understandings gleaned } \\
\text { from collected data. }\end{array}$ \\
\hline \multicolumn{4}{|c|}{ Phase V Plan for Future Action } \\
\hline $\begin{array}{l}\text { All teams are planning } \\
\text { what they will do } \\
\text { differently as a result } \\
\text { of the study, what they } \\
\text { will recommend to } \\
\text { others, and how they } \\
\text { will disseminate results } \\
\text { to benefit others. }\end{array}$ & $\begin{array}{l}\text { Some teams are planning } \\
\text { what they will do } \\
\text { differently as a result of } \\
\text { the study, what they will } \\
\text { recommend to others, } \\
\text { and how they will } \\
\text { disseminate results to } \\
\text { benefit others. }\end{array}$ & $\begin{array}{l}\text { Teachers only are } \\
\text { planning what they will } \\
\text { do differently as a result } \\
\text { of the study, what they } \\
\text { will recommend to } \\
\text { others, and how they } \\
\text { will disseminate results } \\
\text { to benefit others. }\end{array}$ & $\begin{array}{l}\text { No instructional teams } \\
\text { planning are what they } \\
\text { will do differently as a } \\
\text { result of the study, what } \\
\text { they will recommend to } \\
\text { others, and how they } \\
\text { will disseminate results } \\
\text { to benefit others. }\end{array}$ \\
\hline
\end{tabular}

